\title{
Oblique meniscomeniscal ligament: a normal variant
}

\author{
Hee Kyung Kim • Tal Laor
}

Received: 15 December 2008/Accepted: 24 December 2008/Published online: 4 February 2009

(C) Springer-Verlag 2009

A 13-year-old boy with chronic right knee pain underwent MR imaging evaluation. The study revealed a cord-like structure (Fig. 1, arrow) originating from the anterior horn of the medial meniscus and coursing through the intercondylar notch and inserting on the posterior horn of the lateral meniscus. On a sagittal image, there was a linear fibrous band lying inferior to the posterior cruciate ligament (Fig. 2, arrow) simulating the double posterior cruciate ligament sign seen with bucket-handle meniscal tears. This linear structure represents a medial oblique meniscomeniscal ligament. No abnormality was identified to account for the child's pain.

The four ligaments that connect the medial and lateral menisci are: the anterior transverse meniscal ligament (58\%

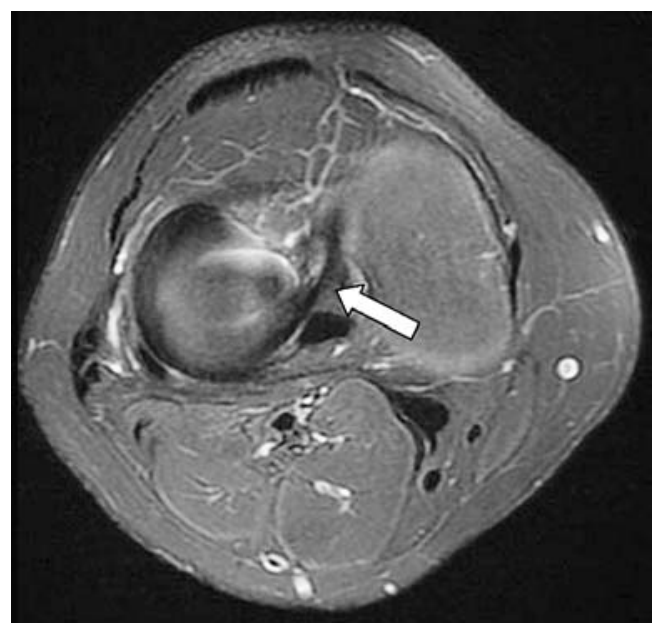

Fig. 1 Axial T2-weighted image

\footnotetext{
H. K. Kim• T. Laor $(\bowtie)$

Department of Radiology,

Cincinnati Children's Hospital Medical Center,

3333 Burnet Ave.,

Cincinnati, OH 45229, USA

e-mail: tal.laor@cchmc.org
}

incidence), the posterior transverse meniscal ligament (1-4\%), and two oblique meniscomeniscal ligaments, medial and lateral, named by their anterior attachments $(1-4 \%)$ [1]. The oblique meniscomeniscal ligament should not be mistaken for a displaced meniscal fragment from a flap or bucket-handle tear [2].

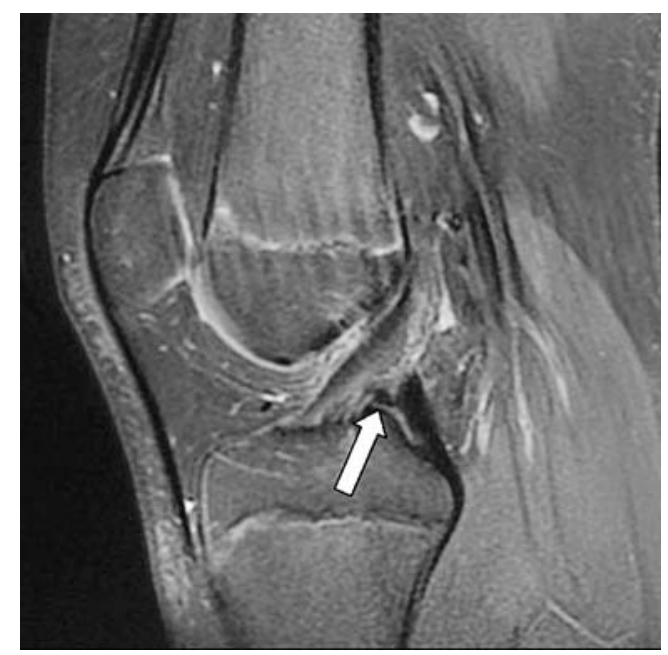

Fig. 2 Sagittal intermediate-weighted image

\section{References}

1. Anderson MW (2002) MR imaging of the meniscus. Radiol Clin North Am 40:1081-1094

2. Sanders TG, Linares RC, Lawhorn KW et al (1999) Oblique meniscomeniscal ligament: another potential pitfall for a meniscal tear - anatomic description and appearance at MR imaging in three cases. Radiology 213:213-216 